\title{
Luzmán y Castrucho en Roma antes y después del Saco: construcción dramática de personajes y ciudad en dos comedias de Lope de Vega*
}

\section{Luzmán and Castrucho in Rome Before and After the Sack: Dramatic Construction of Characters and City in two Lope de Vega's}

\section{Santiago Restrepo Ramírez}

https://orcid.org/0000-0003-0809-5078

Universidad de los Andes

COLOMBIA

srestreporamirez@uniandes.edu.co

[Hipogrifo, (issn: 2328-1308), 9.2, 2021, pp. 377-388]

Recibido: 08-02-2021 / Aceptado: 30-03-2021

DOI: http://dx.doi.org/10.13035/H.2021.09.02.28

Resumen. En este artículo se estudia la construcción dramática de Roma en dos comedias tempranas de Lope de Vega -El caballero del milagro y El galán Castrucho- y su relación con Luzmán y Castrucho, sus protagonistas. El tiempo histórico en que se desarrollan ambas obras es cercano -el reinado del emperador Carlos V-, pero las separa un episodio traumático para la ciudad: el Saco de Roma. Teniendo esto en cuenta, se examina no solo cómo cambia la ciudad, sino cómo esta circunstancia afecta a los protagonistas de nuestras obras.

Palabras clave. Lope de Vega; Roma; Saco de Roma; El caballero del milagro; El galán Castrucho.

* Este artículo se beneficia de mi participación en el proyecto «Edición y estudio de treinta y seis comedias de Lope de Vega» (PGC2018-094395-B-100) y de mi proyecto FAPA (Fondo de Apoyo para Profesores Asistentes), financiado por la Universidad de los Andes (Bogotá, Colombia). 
Abstract. This article studies the dramatic construction of Rome in two early comedies by Lope de Vega -El caballero del milagro and El galán Castrucho- and its relationship with Luzmán and Castrucho, their protagonists. The historical time in which both works are developed is close -the reign of Emperor Charles $V-$, but they are separated by a traumatic episode for the city: the Sack of Rome. Taking this into account, we examine not only how the city changes, but also how this circumstance affects the protagonist of our works.

Keywords. Lope de Vega; Rome; Sack of Rome; El caballero del milagro; El galán Castrucho.

«Todos los caminos llevan a Roma», reza la frase proverbial. Explica la ficha del Refranero multilingüe (s. v.) del Centro Virtual Cervantes que su idea clave es el «esfuerzo» y que la paremia «alude a la posibilidad de conseguir un mismo objetivo por caminos distintos». Dejando de lado su sentido y tomándolo al pie de la letra, cabría preguntarse a qué Roma se refiere: ¿a la Ciudad Eterna o a la «gran puttana y gran prostituta de Babilonia»' ', como la llamaban los protestantes? La ciudad, por decirlo con un título magnífico de Claudio Guillén, está «entre lo uno y lo diverso». Señalaba Italo Calvino, a propósito de su obra Le città invisibili publicada en 1972, que «Las ciudades son un conjunto de muchas cosas: memorias, deseos, signos de un lenguaje; son lugares de trueque, como explican todos los libros de historia de la economía, pero estos trueques no lo son sólo de mercancías, son también trueques de palabras, de deseos, de recuerdos» ${ }^{2}$. Y, tal vez, la imagen que nos regala el Marco Polo de Calvino alumbre mejor la idea que quería expresar usurpando el título de Guillén: «En esta ola de recuerdos que refluye la ciudad se embebe como una esponja y se dilata. Una descripción de Zaira tal como es hoy debería contener todo el pasado de Zaira» ${ }^{3}$. Desde luego las ciudades se construyen en relación con sus habitantes, con los individuos y las masas, pero, al mismo tiempo, los construyen a ellos, a nosotros. Lo intuye también Marco Polo: «La ciudad se te aparece como un todo en el que ningún deseo se pierde y del que tú formas parte, y como ella goza de todo lo que tú no gozas, no te queda sino habitar ese deseo y contentarte» ${ }^{4}$. Estos apuntes sobre la ciudad, estas sugerencias de Calvino y su Marco Polo, me permiten introducir y contextualizar el tema de este ensayo: cómo se construye Roma en dos comedias tempranas de Lope -El caballero del milagro (1593) y El galán Castrucho (h. 1598) $)^{5}$ y cómo la habitan sus dos protagonistas. 
Debo empezar por señalar que, si bien ambas comedias transcurren en Roma ${ }^{6}$, su tiempo difiere sutil pero abismalmente: El caballero del milagro se desarrolla en tiempos de «Carlos Quinto, príncipe invictísimo» (v. 2358), posterior a la batalla de Pavía (1525), según las quejas de Filiberto - «quiere el cielo que pierdo cuanto había / sacado de Pavía» vv. 2457-2458- pero anterior al Saco de Roma7. El galán Castrucho, por su parte, representa la ciudad posterior al traumático evento, en el que el protagonista dice haber participado:

CASTRUCHO Donde se me ofrece, que para treinta años voy y he servido desde trece: sobre Roma con Borbón me hallé en aquella ocasión, y en Santángel con el Papa sobre quitar de la capa a Godofre de Bullón (vv. 629-636)8.

El abismo que separa ambas comedias nos impide aceptar que estamos ante la misma ciudad. Lo explica Joset: «Desde luego el Saco de Roma de 1527, que causó un terremoto espiritual en toda la cristiandad y fue considerado como un castigo divino por la anterior libertad de costumbres, no arregló las cosas ni del hampa ni de las cortesanas de alto vuelo, pero el rebrote de austeridad y represión sexual tenía campo libre para crecer y prosperar» ${ }^{9}$. «Roma ya no volvió a ser la misma» ${ }^{10}$, sentencia Doménech.

En El caballero del milagro percibimos -mediada por la «capacidad visual del lenguaje» que estudió Arellano ${ }^{11}$ - una ciudad admirable, imponente, que merece el laus urbis con que Beatriz saluda a la majestuosa Roma:

BEATRIZ No me acabo de admirar...

¡Qué bravas torres y templos,

qué soberbios edificios,

6. No hay unanimidad crítica a propósito del escenario geográfico de El galán Castrucho: Doménech, 2000, p. 29, propone los puertos napolitanos o el mismo Nápoles, «aunque bien puede ser un puerto de la Toscana o de Liguria»; Molina, en su ed. de El galán Castrucho, p. 1090, nota, que coincide con Oleza, 1991, p. 166, defiende que es Roma esgrimiendo los topoi capitalinos -«San Juan» (v. 159), «la Calle Nueva» (v. 471), «San Clemente» (v. 1577) - y propone que «la marina del puerto» (v. 2101) es fluvial, no marítima. Acepto los argumentos de Molina.

7. Para el tiempo de la ficción ver Oleza, 1991, p. 166, Doménech, 2007, pp. 12-14 y Restrepo y Valdés, en su ed. de El caballero del milagro, pp. 979-980.

8. Molina, en su ed. de El galán Castrucho, p. 1090, nota, sostiene que «Sobre las fechas en que se ambienta la comedia podemos precisar más: Castrucho manifiesta tener "treinta" años, hacer servido "desde trece" y haber estado en Roma durante el Saco. Si hiciéramos el máximo caso de estos datos, no podríamos estar más allá del segundo lustro tras 1527».

9. Joset, 2013, p. 355.

10. Doménech, 2007, p. 14.

11. Arellano, 1999. Ver también Vega Ramos, 1992, Vitse, 1996, y Azaustre Galiana, 2009. 


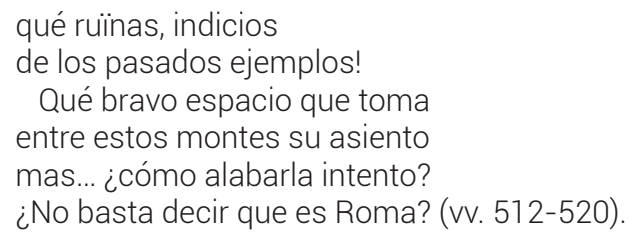

El paisaje urbano impresiona a Beatriz y a nosotros, espectadores que vemos a través de sus palabras. Volviendo a la imagen de Marco Polo en Le città, la cortesana francesa percibe las líneas que se dibujan en la palma de la ciudad, ve indicios de su pasado, de una grandeza que se extiende hasta el presente. Filiberto, siguiendo a Beatriz, subraya los ilustres personajes que la habitaron: «Esta fue / del mundo la gran cabeza / [...] / esta fue la antigua madre / de Césares y Cipiones, / hija de aquellos varones / que a Marte tienen por padre» (vv. 521-528). El personaje señala espacios que son escenarios de hechos famosos: «Aquí Virgíneo mató / a su hija; allí, Lucrecia, / antes loca y después necia, / yerro con hierro sacó» (vv. 533-536). La ciudad se nos presenta a los ojos y la lista de personajes y hechos famosos provoca la graciosa protesta de Lombardo: «iNo hemos hallado mesón / y andamos de calle en calle / y agora querrás contalle / la vida de Cicerón!» (vv. 553-556).

Pero en El caballero del milagro Roma no solo es su pasado, también es su presente, que tampoco carece de esplendor y de lujo, aunque en menor medida. Vemos pasearse por ella un Patricio y su esposa, ambos con capacidad de alquilarles casas, contratarles criados y darles magníficos regalos a sus respectivos amantes: «en otra casa la ha puesto / [...] / Pues hale dado vestidos / y joyas de mil ducados, / escuderos y crïados / con raciones y partidos» (vv. 2238-2241). Luzmán, según noticias que nos proporciona su criado Tristán, se codea fuera del escenario con «príncipes y grandes» (v. 1536): «es cosa de locura lo que estiman / que hable, escriba o cuente alguna cosa» (vv. 1537-1538). De refilón, la ciudad se presenta con un comercio abierto y vivaz: un milanés tiene tienda de textiles donde compra las cintillas Otavia; la casa de alquiler «tiene aposento / que el Rey puede entrar en él» (vv. 1852-1853), lleno de sillas y proveído de cojines de terciopelo «morado» para ir a misa; resumen de esta situación es la bonanza de Otavia que se descubre al final: «aunque pobre me imaginas, / todas estas mujeres / de estrados, telas, ropas y cortinas / pueden ser mis crïadas» (vv. 2795-2798). Sin embargo, Roma es una metrópoli que no se deja definir tan fácilmente: su tamaño y su densidad de población dan cabida a otras caras de la ciudad, de sus bajos fondos y su corrupción:

LUZMÁN Que murió puedes creello

y lo contrario es malicia, pero como era extranjero y Roma es grande, ocultóse y esta sospecha acabóse con diligencia y dinero, que cualquier delito encubre (vv. 2120-2126) ${ }^{12}$.

12. Cañas Murillo, 2009, p. 162, defiende la importancia de la ambientación en nuestra comedia. 
Esta Roma, pues, es escenario ideal para quien, como Luzmán, tiene altas e ilegítimas aspiraciones ${ }^{13}$. La ciudad, su lujo, sus oportunidades económicas y sociales - donde el dinero y el engaño tienen un papel protagónico-, alienta y promueve los deseos de nuestro rufián. Dan ganas de fantasear que Luzmanillo conociera el coloquio Ementita nobilitas de Erasmo y siguiera al pie de la letra las enseñanzas de Néstor: «Lo primero que has de hacer es exiliarte de tu patria. [...] Intégrate en un grupo de jóvenes de una nobleza reconocida. [...] Enseguida empezarán a sospechar que eres del mismo rango de aquellos con los que te relacionas» ${ }^{14}$. Aunque no es explícito, el lugar que sugiere Néstor debe cumplir con ciertos requisitos de riqueza y estar habitado por personajes de la nobleza. Luzmán escoge Roma y actúa según las recomendaciones:

TRISTÁN ¿Pues verle andar con príncipes y grandes?

Es cosa de locura lo que estiman que hable, escriba o cuente alguna cosa; danle su mesa, asiéntanle a su lado, honralle más que a un igual suyo pueden, nunca le faltan cuentos, nuevas, fábulas, sucesos de Alemania, España y Flandes (vv. 1536-1542).

Así, entre la Ciudad Eterna de los nobles y los lujos, y la «gran puttana» de cortesanas y rufianes de diverso pelambre, Luzmán se mueve como pez en el agua, sacando partido de ambos mundos en la incesante búsqueda de su ascenso social: «Si pesco tanto dinero, / yo doy conmigo en España» (vv. 2264-2265); «que si cojo tanta suma / caballero voy a España» (vv. 2310-2311). En su forma de vida romana, justamente, está el milagro de nuestro caballero Luzmán ${ }^{15}$, como señaló Guarino: «Si tratta di una Roma senza religiosità e senza clero, in cui l'unico "milagro" possibile è quello realizzato dal protagonista di vivere al di sopra dei propri mezzi e ben al di là del suo originario status di plebeyo»'16.

De la lujosa y magnífica Roma de El caballero del milagro apenas quedan vestigios en El galán Castrucho; conserva, eso sí, la misma vitalidad carnal, sensual, monetaria y el cómico imperio del engaño y la mentira. Señala Doménech que los tres actos de la comedia son nocturnos ${ }^{17}$, empezando al atardecer, en un tiempo simbólico que ilustra con un famoso verso lopesco: «noche, fabricadora de

13. En palabras de Guarino, 2001, p. 157: «Il maggiore motivo di interesse risiede, probabilmente, nella caratterizzazione del protagonista, avventuriero affascinante e spregiudicato in una Roma che sembra costituirsi in fondale ideale della sua vertiginosa ascesa così come della sua precipitosa caduta».

14. Erasmo, 2011, p. 622. La comedia y el coloquio erasmiano aguantan una comparación más amplia y profunda que estoy preparando.

15. Analizando el modelo temprano de la comedia lopesca, señala acertadamente Arellano, 1999, pp. 85 y 86 , que en esta «lo que hay son galanes sistemáticamente antiheroicos, venales, lujuriosos, cobardes, tacaños y amorales» que en Las ferias de Madrid «maldicen de la costumbre de las ferias, hablan de burlas a mujeres, se califican de caballeros del milagro».

16. Guarino, 2001, p. 161

17. Doménech, 2000a, p. 56. 
embelecos» ${ }^{18}$. Sin duda tiene razón. Añadiría yo que esa oscuridad-esencial para el desarrollo del argumento - también impide ver el espacio y la ciudad se difumina y casi desaparece en la penumbra. En este sentido, creo que no es casual la ambigüedad en la ubicación espacial de la trama y el debate que se ha desprendido de ella: las referencias a la ciudad son pocas - la iglesia de «San Juan» (v. 159) de Letrán, al parecer ${ }^{19}$, «la Calle Nueva» (v. 471) y la iglesia de «San Clemente» (v. 1577), cercana a la primera aquí citada ${ }^{20}-y$, aunque permiten entrever un boceto de cartografía romana, domina sobre el espacio una especie de silencio. Silencio, digo, que ha planteado dudas y cierto debate en cuanto a la ubicación espacial de la acción: Doménech, por ejemplo, habla de «un puerto», y más adelante subraya que «cuál sea ese puerto es difícil de asegurar»; su propuesta es también abierta y mantiene la duda, pues podría tratarse de algún puerto napolitano, «o quizás el mismo Nápoles, centro del dominio español en Italia, aunque bien puede ser un puerto de la Toscana o de Liguria» ${ }^{21}$. La identificación del espacio con una ciudad costera se sustenta en la referencia a la «marina del puerto» (v. 2101), pero Molina advierte sobre la posibilidad de que sea un «puerto» fluvial y no marítimo, hecho que, sumado a los topoi capitalinos arriba aludidos ${ }^{22}$, permiten aceptar que estamos ante «la Roma de Castrucho», en palabras de Oleza ${ }^{23}$. Con todo, es evidente que la ausencia de descripciones -o el deliberado silencio-, no lo olvidemos, también tiene un valor visual, en este caso crea oscuridad. Así esta oscuridad y la imagen brumosa de la ciudad se alimentan mutuamente: ya no estamos en la Roma iluminada, en la Ciudad Eterna que causa la admiración de Beatriz, sino en un espacio confuso, construido a través de calles innominadas donde se siente a cada paso la presencia del ejército vencedor, como bien describe Teodora: «Juntos están agora, / en aquestas villetas alojados, / de gente vencedora / mil capitanes, quince mil soldados» (vv. 316-319). De hecho, todos los personajes, salvo las mujeres y criados, son militares de variados rangos, eso sí, cada uno «fanfarrón soldado» (v. 887).

La oscuridad permite construir la noche romana, repleta de altercados violentos y ocultamientos. Buen ejemplo es el último pasaje del primer acto, donde apenas importa dónde están más allá de saber que es una escena callejera; las acotaciones dan buena cuenta del desarrollo del episodio: «Arrímanse a una parte Castrucho y Escobarillo / El Sargento y Fortuna» (v. 927 acot.); mientras la joven y el militar dialogan, sin que lo vean «Haga Castrucho muestras de querelle acometer a lo lebrón» (v. 946 acot.); casi simultáneamente, «Salgan don Jorge, alférez, y dos soldados, Mendoza y Guzmán» (v. 947 acot.), «tres hombres muy embozados»

18. Lope de Vega, Rimas, I, «Soneto CXXXVII», pp. 487-488.

19. Comenta Molina, en su ed. de El galán Castrucho, en nota al verso que también podría tratarse de la menos conocida iglesia de San Juan de los Florentinos.

20. Molina, en su ed. de El galán Castrucho, p. 1090, nota.

21. Doménech, 2000a, pp. 20 y 57.

22. Molina, en su ed. de El galán Castrucho, p. 1090, nota.

23. Oleza, 1991, p. 166. Véase también el reciente artículo de Piqueras Flores, 2020, sobre las comedias de ambientación italiana de Lope, en este ubica nuestra comedia en la capital italiana. 
(v. 948), comentará asustado Álvaro, el sargento, ante el ataque. El cuadro se repite, pero ahora es don Jorge quien ocupa el lugar del sargento: «Entre el Capitán y Pradelo y Belardo, sus criados» (v. 966 acot.) y, tras unos pocos insultos, «Váyanse todos tras él acuchillándole, quede Fortuna sola. Sale Castrucho, que ha estado a la mira, la espada desnuda» (v. 977 acot.). Solo la oscuridad de las calles y su construcción escénica a través de las palabras y del movimiento de los actores, de sus gestos, permite el desarrollo de semejante confusión ${ }^{24}$. También la negrura y el actuar que propicia en los personajes nos ilustra una ciudad muy distinta: ya no estamos en la Roma donde todavía se escucha el eco y se ven los vestigios de su heroico pasado - «hija de aquellos varones / [...] / que a Marte tienen por padre» (vv. 521-528) que alababa Filiberto en El caballero del milagro-, sino en una ciudad en ruinas, apenas reconocible, donde los héroes se han convertido en auténticos soldaduchos fanfarrones - o Castruchos, que, como explica Molina, «su dimensión cómica está caracterizada ya en su propio nombre (curiosamente un italianismo), donde coexisten la etimología de la familia "castrense", a la que se añade el sufijo peyorativo -ucho, de tradicional connotación jocosa» ${ }^{25}$ -

La Roma de Castrucho, pues, es la de los militares fanfarrones, que dedican su tiempo al juego y a visitar lupanares, a la vida nocturna y desvergonzada. El dinero mantiene su importancia en la comedia, pero se percibe menos su esplendor: si en El caballero del milagro los regalos son sustanciosos, en El galán Castrucho apenas pespuntan. Los soldados se quejan del precio de las prostitutas - «iQué caras que se nos venden!» (v. 217) - y de su decadencia: «Aún ya si tuvieran caras / pudieran venderse caras: / que caras sin caras ofenden» (vv. 218-220). Siguiendo esta lógi$\mathrm{ca}$, la historia de la ciudad se traduce en términos prostibularios, como se ve en la promesa que el protagonista le hace a Héctor:

CAStRUCho Calla, príncipe, que quiero que goces de hoy más mil damas y que deshagas más famas que cortó cabezas Nero. Traeréte dos mil mozuelas, y no de aquestas perdidas sino las de ayer nacidas, con su flor como ciruelas. Vete en paz, y goza aquésta, que a la tarde la tendrás (vv. 1149-1158).

24. Para el montaje de la obra, Doménech, 2000b, Malonda, 2000 y Camacho, 2000.

25. Molina, en su ed. de El galán Castrucho, p. 1091. También Di Pinto, 2000, p. 157, que, por otra parte, aporta excelentes consideraciones sobre el cambio de título de la comedia, de rufián a galán, y sobre su posición en el arte dramático de Lope: «punto de encuentro de todo el teatro anterior y el germen de todo lo venidero» (p. 159). 
La miseria de este mundo se reflejará hasta en el apestoso olor de las calles y de las inmundicias que vuelan por las ventanas y ensucian a estos soldaduchos: «Callad, no venga una teja, / que el agua limpiarse ha» (vv. 1831-1832), dice Héctor; responde Álvaro, «iQué bellacamente huele!» (v. 1833) ${ }^{26}$. Oleza ha descrito magníficamente este mundo de El galán Castrucho:

La mirada costumbrista, tan característica en Lope, se impregna en estas comedias de un realismo cuartelario y rufianesco: soldados de fortuna que se alistan para escapar del hambre o vivir cómodamente a costa del Rey [.... Algunos se hacen acompañar de mujeres a las que prostituyen y chulean [...], y a otros es más fácil encontrarlos en lupanares o negociando con rufianes y alcahuetas que en los cuarteles. [...] La calle y la noche son el escenario natural de la vida soldadesca27.

A diferencia de lo que ocurre en El caballero del milagro, en El galán Castrucho se apela a la necesidad como justificación. Teodora es «una pobre vergonzante» (v. 1590) que tiene «una hija tan bella / que dejó de ser doncella / por no tener qué comer» (vv. 1599-1601); dice, además, que «Las dos somos de Castilla, / de la ciudad de Sevilla; / he criado esta cuitada, / que me la dejó encargada / su madre desde chiquilla, / que murió, su buena madre» (vv. 726-732). Castrucho, según lo vemos en escena, actúa siempre en su beneficio, pero en uno inmediato, sin perspectiva de futuro, como bien señala la misma Teodora, que lo define genialmente:

TEOd..] Es un picaño, un feo,
un público rufián que te ha traído
a Italia con deseo
de comerte las carnes y el vestido,
que apenas tienes prenda
que no la coma, juegue, empeñe o venda.
¿A qué piensas que viene
al ejército agora este bellaco?
¿Por codicia que tiene
de hacerte rica en el primero saco?
¡Ay, qué mal que lo entiendes,
que sólo aguarda y cobra lo que vendes!
(vv. 293-304).

Y a lo máximo que aspira Castrucho es a ganarse el favor del maese de campo, don Rodrigo, porque «le da su mesa y cama y favorece» (v. 1023). Y continúa:

\footnotetext{
Quiero que me conozca y que se informe de mis temeridades y locuras y sepa lo que soy con una espada,
}

26. Camacho, 2000, p. 111, explica, a propósito del montaje de la obra, que «los efectos [lumínicos] que se crearon fueron, fundamentalmente, para apoyar las meadas de todo el ejército en cubetas; se añadieron espejos en el fondo para reflejar la luz de los bastidores en primer término, y así hacer efectos de agua». Ver también Gitlitz, 1980.

27. Oleza, 1991, p. 172. 
porque, con su favor, todos aquestos

huyan de mí como las brujas huyen

la siempre verde ruda y amapolas (vv. 1024-1029).

Las aspiraciones de Castrucho palidecen frente a las de Luzmán. Pero es que la Roma de El galán ya no palidece, sino que desaparece a la luz de la de El caballero: las ciudades, los espacios, juegan un papel determinante en la construcción de la obra. La ambición de Luzmán tiene su correspondencia en la Roma que habita, magnífica y amoral; y no solo sus aspiraciones, el mismo personaje es, como la ciudad, belleza que esconde vacío. Unos versos del rufián lo explican a él mismo y a la ciudad en idéntica medida: «¿A quién no engaña la muestra / de aquesta bella portada? / No llega a su entendimiento / lo que dentro de ella pasa; / todo es portada la casa, / que dentro no hay aposento» (vv. 719-724). En contraposición, Castrucho es tan feo y desagradable como las nocturnas y olorosas calles romanas y su alcance de miras parece limitado por la oscuridad - física y simbólica- de la ciudad.

No sobra recalcar que estas dos ciudades, la misma y distintas simultáneamente, a pesar de sus claroscuros - 0 , más bien, justamente por ellos- son escenario de comedia, donde la risa y el juego tienen un papel fundamental. Lo señala Oleza: «la distancia en años y la ubicación de la intriga en otro país [aquí en Roma, específicamente], otorgan a Lope un margen de libertad crítica y de desprejuiciamiento moral que sería imposible en las tragedias y tragicomedias de la honra» ${ }^{28}$. Dos ciudades y dos personajes que parecen los mismos pero que en sus matices se diferencian y provocan dos risas muy distintas: una moralizante que castiga las pretensiones de Luzmán y celebra su caída; otra alegre, popular, diríamos con Bajtín «carnavalesca» - no se nos olvide la importancia de la sensualidad y lo escatológico en esta comedia-, que aplaude y premia el ingenio de Castrucho.

En conclusión, estas dos comedias nos presentan un par de personajes de la misma familia moldeados en buena medida por la ciudad -la misma y distinta-, por sus espacios, por sus luces y sus sombras. No son idénticas estas dos Roma y, por tanto, Castrucho y Luzmán no pueden ser los mismos. Lo advertía también Marco Polo:

Hay que guardarse de decirles que a veces ciudades diferentes se suceden sobre el mismo suelo y bajo el mismo nombre, que nacen y mueren sin haberse conocido, incomunicables entre sí. En ocasiones hasta los nombres de los habitantes permanecen iguales, y el acento de las voces, e incluso las facciones; pero los dioses que habitan bajo esos nombres y en esos lugares se han marchado sin decir nada y en su lugar han anidado dioses extranjeros ${ }^{29}$.

Habría que matizar que nuestras dos Romas no son «incomunicables entre sí», pues conservan algunos importantes puntos en común, sin embargo, si son muy distintas. Terriblemente, estas dos comedias de Lope nos alumbran el presente: 
nuestras ciudades - Barcelona, Bogotá, Roma, Pamplona- ya no son las mismas que hace unos cuantos meses, estamos asistiendo a un relevo de dioses y tal vez nosotros no podamos volver a ser los mismos.

\section{BiBLIOgRAFíA}

Alcalá Galve, Ángel, «Erasmo, Alfonso de Valdés y el Saco de Roma a cuenta de Dios», en Erasmo en España. La recepción del humanismo en el primer renacimiento español, Madrid, Sociedad Estatal para Acción Cultural Exterior, 2002, pp. 80-95.

Arellano, Ignacio, Convención y recepción. Estudios sobre el teatro del Siglo de Oro, Madrid, Gredos, 1999.

Azaustre Galiana, Antonio, «Recursos retóricos en el teatro del Siglo de Oro: el caso de la Evidentia», en El teatro del Siglo de Oro. Edición e interpretación, ed. Alberto Blecua, Ignacio Arellano y Guillermo Serés, Madrid / Frankfurt am Main, Iberoamericana / Vervuert, 2009, pp. 29-49.

Calvino, Italo, Las ciudades invisibles, ed. al cuidado de César Palma, trad. Aurora Bernárdez, Madrid, Siruela, 2018 [1. ${ }^{a}$ ed., 1998].

Camacho, Miguel A., «Huyendo de la luz de los clásicos», en Lope de Vega, El rufián Castrucho, versión y ed. Fernando Doménech, Madrid, RESAD / Editorial Fundamentos, 2000, pp. 107-111.

Cañas Murillo, Jesús, «En los orígenes del tipo de figurón: El caballero del milagro (1593), comedia del destierro de Lope de Vega», en En buena compañía. Estudios en honor de Luciano García Lorenzo, coord. Joaquín Álvarez Barrientos, Óscar Cornago Bernal, Abraham Madroñal Durán y Carmen Menéndez Onrubia, Madrid, Consejo Superior de Investigaciones Científicas, 2009, pp. 159-170.

Centro Virtual Cervantes, Refranero multilingüe, en línea [consulta: 06/10/2020].

Delicado, Francisco, La Lozana andaluza, ed. Folke Gernert y Jacques Joset, Madrid, Real Academia Española, 2013.

Di Pinto, Elena, «De rufián a galán (1598)», en Otro Lope no ha de haber. Atti del Convegno internazionale su Lope de Vega, 10-13 febraio 1999, ed. Maria Grazia Profeti, Firenze, Alinea Editrice, 2000, vol. II, pp. 151-158.

Doménech, Fernando, «Estudio de El rufián Castrucho», en Lope de Vega, El rufián Castrucho, versión y ed. Fernando Doménech, Madrid, RESAD / Editorial Fundamentos, 2000a, pp. 11-75.

Doménech, Fernando, «La puesta en escena de El rufián Castrucho hoy», en Otro Lope no ha de haber. Atti del Convegno internazionale su Lope de Vega, 10-13 febraio 1999, ed. Maria Grazia Profeti, Firenze, Alinea Editrice, 2000b, vol. III, pp. 177-189. 
Doménech, Fernando, «Análisis de El arrogante español», en Lope de Vega, El arrogante español o Caballero de milagro, versión Guillermo Heras y Fernando Doménech, ed. Fernando Doménech, Madrid, RESAD / Editorial Fundamentos, 2007, pp. 9-45.

Erasmo, Coloquios, trad. y notas Pedro Rodríguez Santidrián, en Erasmo, Madrid, Gredos, 2011, pp. 425-655.

Fernández Rodríguez, Daniel, «Nuevos datos acerca de los repertorios teatrales en el primer catálogo de El peregrino en su patria», Studia Aurea, 8, 2014, pp. 277-314.

Gitlitz, David M., «El galán Castrucho: Lope in the Tradition of Bawdy», Bulletin of the Comediantes, 31, 1980, pp. 3-9.

Guarino, Augusto, «L'Italia sulla scena nel teatro spagnolo della seconda metà del Cinquecento. II caso di El caballero del milagro di Lope de Vega», in Italia e Spagna nella seconda metà del Cinquecento. Atti del colloquio, Napoli, IUO, 21-23 ottobre 1999, Napoli, Istituto Universitario Orientale, 2001, pp. 157-173.

Guillén, Claudio, Entre lo uno y lo diverso. Introducción a la literatura comparada (ayer y hoy), Barcelona, Tusquets, 2005.

Malonda, Antonio, «Un proceso interrumpido de puesta en escena», en Lope de Vega, El rufián Castrucho, versión y ed. Fernando Doménech, Madrid, RESAD / Editorial Fundamentos, 2000, pp. 77-88.

Morley, S. Griswold, y Bruerton, Courtney, Cronología de las comedias de Lope de Vega. Con un examen de las atribuciones dudosas, basado todo ello en un estudio de su versificación estrófica, versión española de María Rosa Cartes, Madrid, Gredos, 1968.

Oleza, Joan, «La propuesta teatral del primer Lope de Vega», en Teatro y prácticas escénicas, dir. Joan Oleza, València, Institució Alfons el Magnànim, 1984, pp. 251-308.

Oleza, Joan, «La comedia de pícaros de Lope de Vega: una propuesta de subgénero», en Comedias y comediantes. Estudios sobre el teatro clásico español, ed. Manuel Diago y Teresa Ferrer, Valencia, Universitat de València, 1991, pp. 165-187.

Piqueras Flores, Manuel, «Las comedias de ambientación italiana de Lope de Vega: Artelope como punto de partida», Anuario Lope de Vega. Texto, literatura y cultura, 26, 2020, pp. 470-499.

Vega Carpio, Lope de, El caballero del milagro, ed. Santiago Restrepo y Ramón Valdés, en Comedias de Lope de Vega Carpio. Parte XVI, coord. Luis Sánchez Laílla, Madrid, Gredos, 2016, vol. I, pp. 971-1153.

Vega Carpio, Lope de, El galán Castrucho, ed. Julián Molina, en Comedias de Lope de Vega. Parte IV, coord. Luigi Giuliani y Ramón Valdés, Lérida, Milenio-Universitat Autònoma de Barcelona, 2002, vol. III, pp. 1085-1220. 
Vega Carpio, Lope de, Rimas, ed. F. Pedraza Jiménez, [Cuenca], Universidad de Castilla-La Mancha, 1993, 2 vols.

Vega Ramos, María José, El secreto artificio. Maronolatría y tradición pontaniana en la poética del Renacimiento, Madrid, CSIC, 1992.

Vitse, Marc, «Sobre los espacios en La dama duende: el cuarto de don Manuel», en De hombres y laberintos. Estudios sobre el teatro de Calderón, ed. Ignacio Arellano y Blanca Oteiza, número monográfico de Rilce. Revista de Filología Hispánica, 12.2, 1996, pp. 337-356. 